\section{Research Square}

\title{
The Bidirectional Temporal Relationship Between Headache and Affective Disorders: Longitudinal Data from the HUNT Studies
}

Knut Hagen ( $\sim$ knut.hagen@ntnu.no)

St. Olavs Hospital https://orcid.org/0000-0003-2111-8895

\section{Samita Giri}

NTNU Universitetsbibliotek: Norges teknisk-naturvitenskapelige universitet

Erling Andreas Tronvik

NTNU Det Medisinske Fakultet DMF: Norges Teknisk-Naturvitenskapelige Universitet Fakultet for Medisin og Helsevitenskap

Research article

Keywords: Migraine, epidemiology, general population, follow-up

Posted Date: November 16th, 2021

DOI: https://doi.org/10.21203/rs.3.rs-1070525/v1

License: (a) (1) This work is licensed under a Creative Commons Attribution 4.0 International License. Read Full License 


\section{Abstract}

Background Few prospective population-based studies have evaluated the bidirectional relationship between headache and affective disorder. The aim of this large-scale population-based follow-up study was to investigate whether tension-type headache (TTH) and migraine had increased risk of developing anxiety and depression after 11 years, and vice-versa.

Methods Data from the Trøndelag Health Study (HUNT) conducted in 2006-2008 (baseline) and 20172019 (follow-up) were used to evaluate the bidirectional relationship between migraine and TTH and anxiety and depression measured by Hospital Anxiety and depression Scale (HADS). The population at risk at baseline consisted of respectively 18,380 persons with HADS score $\leq 7$ and 13,893 without headache, and the prospective data was analyzed by Poisson regression.

Results In the multi-adjusted model, individuals with HADS anxiety (HADS-A) and depression scores (HADS-D) of $\geq 8$ at baseline nearly doubled the risk of migraine (Risk rations (RR) between 1.8 and 2.2) at follow-up whereas a $40 \%$ increased risk (RR 1.4) was found for TTH. Vice versa, the risk of having HADSA and HADS-D scores of $\geq 8$ at follow-up were increased for TTH (RR 1.3) and migraine (RR 1.3-1.6) at baseline. Migraine with aura was associated with $81 \%$ (RR 1.81, 95\% 1.52-2.14) increased risk of HADS-A score of $\geq 8$.

Conclusions In this large-scale population-based follow-up study we found a bidirectional relationship between anxiety and depression and migraine and TTH. For anxiety, this bidirectional association was slightly more evident for migraine than TTH.

\section{Introduction}

Migraine, depression, and anxiety are all ranked as top ten causes of years lived with disability, affecting the health and economy on individuals, and with high economic burden to most countries in Europe [13]. The association between affective disorders and migraine is well established in cross-sectional studies [e.g. 4-8], whereas few longitudinal studies have evaluated the temporal bidirectional relationship between primary headaches and anxiety and depression, and with inconsistent results [9-14]. Methodological differences between studies e.g. regarding sample size and study population may partly explain inconsistent findings [13]. Among the few large-scale longitudinal cohort studies evaluating the bidirectional relationship, a Canadian study of 15,254 individuals reported that persons with migraine were $60 \%$ more likely to develop depression, and vice versa, that individuals with depression were $40 \%$ more likely to develop migraine [13]. On the other hand, a prospective study from the United States who did not find any association between depression and migraine, may have been underpowered to detect this relationship [11]. Little is known, however, about the relationship between migraine and anxiety, and between TTH and affective disorders.

The objective of this prospective large-scale population-based 11-year follow-up study was to evaluate whether anxiety and depression are associated with increased risk of migraine and tension-type 
headache, and whether these primary headache disorders are associated with increased risk of anxiety and depression.

\section{Methods}

\section{Study design}

This is a population-based historical prospective cohort study evaluating the bidirectional relationship between common primary headache disorders and affective disorders.

\section{The HUNT surveys}

The present study used baseline data from the third Trøndelag Health study (HUNT3) performed 20062008 and follow-up data from the HUNT4 study performed 2017- 2019 [15-17]. In both surveys the entire population of the Nord-Trøndelag County aged $\geq 20$ years was invited to answer many health-related items in two different questionnaires (Q1 and Q2), including Q2 questions about headache and anxiety and depression, and to participate in a clinical examination, including measurement of weight and height.

\section{Hospital Anxiety and Depression Scale}

HUNT3 and HUNT4 included the self-administered questionnaire Hospital Anxiety and Depression Scale (HADS), consisting of seven questions each about anxiety (HADS-A) and depression (HADS-D). Each question was scored on a scale of $0-3$, yielding two subscales with a range of $0-21$, with higher scores indicating higher levels of distress. The seven items of HADS-D are relevant for diagnostic criteria of depression in the fifth version of the Diagnostic and Statistical Manual of Mental Disorders (DSM-5) and ICD-11 (World Health organization, 2019), and most of the items of HADS-A are relevant for criteria of generalized anxiety disorder (GAD) for both diagnostic manuals. A study based on HUNT2 $(n=52,265)$ found that HADS was a suitable instrument for assessment in the general population [18]. A review of previous studies has concluded that the cutoff score of 8 give an optimal balance between sensitivity and specificity, both of which are around 0.80 on both subscales [19], whereas the $\geq 11$ cut-off value increases the specificity. In the present study, individuals with HADS-A and HADS-D score between 0 and 7 constituted the reference group (0-14 for total HADS score). These were compared with HADS-A and HADS-D score of $\geq 8$ ( $\geq 15$ for total HADS score). In addition, as recommended by Zigmond and Snaith [20], we also divided the participants with elevated HADS score into two groups: 8-10 indicating possible cases of anxiety or depression, and $\geq 11$ as probable cases (15-21 and $\geq 22$ for total HADS score). The total HADS score are reflecting those with combined depression and anxiety. In the data file distributed by the HUNT research Centre, the total HADS score was extrapolated for those with at five or six completed items on both the HADS-D and the HADS-A, and the sum of completed items were multiplied with $7 / 5$ or $7 / 6$, respectively. 


\section{Headache diagnoses}

HUNT3 and HUNT4 had 14 identical headache questions [15]. The initial screening question was "Have you suffered from headache during the last 12 months?", and those who responded "yes" answered 13 additional questions. Individuals who answered "no" in HUNT3 were included in the population at risk of headache in HUNT4. A slight modification of the criteria of the International Classification of Headache Disorders, third edition (ICHD 3) [21] was used for diagnosing migraine, probable migraine, and tensiontype headache (TTH). The diagnoses were mutually exclusive. As to the modifications of the criteria, individuals would fulfill the migraine criteria even if the attack lasted less than 4 hours, because they were not asked for untreated attacks in the question "How long does the headache usually last?"

We have previously reported the validity of the questionnaire-based headache diagnoses in HUNT3 [22] and HUNT4 [23]. Merged data of two studies based on HUNT3 $(n=293)$ and HUNT4 $(n=232)$ gave the following results; for definitive migraine, the sensitivity was $63 \%$ and specificity $92 \%$ (kappa values 0.57 , $95 \% \mathrm{Cl} 0.44-0.70$ ), for migraine with aura, the sensitivity was $39 \%$ and specificity $95 \%$ (kappa values 0.34 , $95 \% \mathrm{Cl} 0.30-0.38$ ), and or TTH $\geq 1$ days/month, the sensitivity was $97 \%$ and specificity was $71 \%$ (kappa value $0.38,95 \% \mathrm{Cl} 0.31-0.45)[15,22,23]$.

\section{Study population}

The numbers of invited individuals and participants in HUNT3 and HUNT4 are presented in the flow diagram (Figure 1). Out of 50,801 HUNT3 participants (54\% of invited), 33,822 (36\%) also participated in HUNT4. In HUNT4, 56,042 (54\%) aged $\geq 20$ years participated out of 103,800 invited (Fig. 1). Among those who were invited, 41,460 (40\%) answered the headache questions and 40,996 (39\%) had HADS scores.

Population at risk in the present study was selected among those participated in HUNT3 and HUNT4 and had answered questions related to headache, anxiety, and depression in both surveys. Among these, 12,613 ( $12 \%$ out of those invited to HUNT3) lacked information on headache and/or HADS scores. 13,893 (15\%) of HUNT3 participants were headache free at baseline and were recognized as population at risk of developing headache in HUNT4. Likewise, 18,380 (20\%) had HADS score $\leq 7$ in HUNT3 and were considered as population at risk for elevated HADS score in HUNT4.

\section{Confounders}

The selection of potential confounders was based on a review of previous population-based studies [2431]. In the HUNT studies we have previously demonstrated that primary headache disorders and affective disorders both have a strong relationship with age and sex [24, 25], and independent associated with socioeconomic status [26, 27], smoking [28-30] and other lifestyle factors [31]. Thus, in the present study we evaluated the following potential confounders: Age (10-years categories), sex, duration of education 
$\left(\leq 9,10-12\right.$, and $\geq 13$ years), body mass index $(\mathrm{BMI})\left(<25,25.0-29.9\right.$, and $\left.\geq 30 \mathrm{~kg} / \mathrm{m}^{2}\right)$, and smoking (current, previous, and never).

\section{Ethics}

This study was approved by the Regional Committee for Medical and Health Research Ethics, the Faculty of medicine, mailbox 8905, 7491 Trondheim. The approval number was \#2018/2422/Rek Midt. The participants have given written informed consent.

\section{Statistical analysis}

Descriptive analyses of the study population are presented through numbers and percentages for categorical variables and means and standard deviations for continuous variables.

A modified Poisson regression with a robust error variance was used to estimate the following: In the headache free group at baseline in HUN3 (defined as population at risk of headache at follow-up), the association between HADS score at baseline and risk ratios (RRs) of definitive and probable migraine and TTH were evaluated. Furthermore, in the group with HADS score of $\leq 7$ (defined as the population at risk of having elevated HADS score at follow-up), the association between headache diagnoses at baseline and risk ratios (RRs) of elevated HADS score was investigated. Precision of RRs were assessed by $95 \%$ confidence intervals (Cls). We present results for two different statistical models separated by the number of categorical potential confounders included. Model 1 included age, sex, and education level, in model 2 smoking status and BMI were added. Subjects with missing data on smoking status and BMI (Table 1) were included in the analysis to reduce the impact of possible bias. Analyses were performed with the IBM SPSS version 26 (SPSS, Chicago, Illinois, USA)

\section{Results}

Baseline characteristics of the HUNT3 population at risk without headache $(n=13,893)$ and with HADS anxiety and depression score $\leq 7(n=18,380)$ are presented in Table 1. A total of 11,064 ( $80 \%$ of those without headache) also had HADS score $\leq 7$ (Fig. 1). Mean BMI was identical in both population at risk groups. On the other hand, compared to the headache free group, individuals with HADS score $\leq 7$ were younger (mean age 52.3 vs 54.6 years) and more likely to be women (57.6\% vs $52.6 \%$ ). Furthermore, those with HADS score $\leq 7$ were less likely to report hypertension, stroke, and diabetes mellitus than those without headache (Table 1).

\section{The impact of anxiety and depression on the risk of headache in HUNT4}

Among the 13,893 persons without headache in HUNT3, 273 (2.0\%) developed definite migraine, 1438 (10.3\%) TTH and 229 (1.7\%) probable migraine. In the fully adjusted model, HADS-A score of $\geq 8$ nearly 
doubled the risk of having definite migraine (RR 1.75, 95\% 1.27-2.42) and probable migraine (RR 1.76, 95\% 1.24-2.49) whereas a 44\% increased risk was found for TTH (RR 1.44, 95\% Cl 1.22-1.70) (Table 2). For HADS-D score of $\geq 8$ higher risk were found for definite migraine (RR 2.15, 95\% $\mathrm{Cl} 1.45-3.18$ ) and TTH (RR 1.48, 95\% 1.23-1.79), but not evident for probable migraine (RR 1.45, 95\% 0.90-2.35). Individuals with combined anxiety and depression (total HADS score $\geq 22$ at baseline) had more than four times increased risk of developing definite migraine (RR 4.54, 95\% Cl 2.39-8.60) and three times increased risk of developing probable migraine (RR 3.20,95\% $\mathrm{Cl} 1.44-7.13)$, whereas the RR of TTH was 1.64 (95\% $\mathrm{Cl}(1.11-2.41)$ (Table 2).

\section{The impact of headache on the risk of elevated anxiety and depression score in HUNT4}

Among the 18,380 individuals with HADS-A and HADS-D score $\leq 7$ at baseline in HUNT3, 1228 (6.7\%) had HADS-A score between 8-10 and 349 (1.9\%) had HADS-A score $\geq 11$, whereas the corresponding figures for HADS-D was 751 (4.1\%) and 182 (1.0\%) (Table 3). Table 3 shows the impact of headache types in HUNT3 on the risk of two separate elevated HADS score groups in HUNT4, whereas Table 4 present merged data. In the fully adjusted analyses in Table 4 (model 2), the risk of HADS-A score of $\geq 8$ was increased for individuals with definite migraine (RR 1.59, 95\% Cl 1.38-1.82), migraine without aura (RR $1.39,95 \% \mathrm{Cl} 1.15-1.67$ ), migraine with aura (RR 1.81, 95\% Cl 1.52-2.14), probable migraine (RR $1.30,95 \%$ $\mathrm{Cl} 1.09-1.56)$ and TTH (RR 1.29, 95\% $\mathrm{Cl} 1.14-1.47$ ) (Table 4). The risk of HADS-D score of $\geq 8$ was increased for definite migraine (RR 1.26, 95\% Cl 1.02-1.56) and TTH (RR 1.30, 95\% Cl 1.10-1.54). Finally, the risk of having the combination of anxiety and depression (total score of $\geq 15$ ) was increased for definite migraine (RR 1.42, 95\% Cl 1.17-1.71), migraine with aura (RR 1.67, 95\% Cl 1.32-2.10), probable migraine (RR 1.38, 95\% Cl 1.11-1.72) and TTH (RR 1.18, 95\% Cl 1.00-1.39).

\section{Discussion}

In this large-scale population-based study a bidirectional relationship between anxiety and depression with migraine and TTH was found. We identified slightly higher risk ratio for definite migraine than for TTH for anxiety.

\section{Previous studies}

To our knowledge, no previous longitudinal population-based headache studies have evaluated depression or anxiety using HADS score. Thus, direct comparison with other results should be done with cation.

\section{Depression}


In the present study we found approximately $30 \%$ increased risk of depression among patients with migraine or TTH, and that depression at baseline more than doubled risk of migraine, whereas a $40 \%$ increased risk of TTH was found. Accordingly, a questionnaire-based 14-year follow-up study of 36,016 women without depression at baseline, reported that the risk of depression was 1.4 (1.3-1.6) for nonmigrainous headache, 1.5 (1.4-1.8) for migraine with aura, 1.4 (1.3-1.6) for migraine without aura, and 1.6 (1.4-1.8) for past history of migraine [14]. Most of the previous population-based follow-up studies from Canada and US have focused mainly on the temporal relationship between migraine and major depression. For example, a 12-year population-based follow-up of approximately 14,000 individuals aged $>12$ years from Canada demonstrated a bidirectional relationship between migraine and major depressive episodes [13]. Thus, migraine gave a $60 \%$ increased risk (RR 1.6, 95\% $\mathrm{Cl} 1.3-1.9$ ) of major depression, whereas major depression gave $40 \%$ increased risk (RR 1.4, 95\% Cl 1.0-1.9) migraine [13]. A separate publication based on this Canadian population focused on 8-year follow-data of 9,288 participants aged 18-64 years [32]. In sex and age-adjusted analyses they showed that depression was predictive of migraine (HR 1.62, 95\% Cl 1.03 - 2.53) and migraine was predictive of depression (HR 1.55, 95\% $\mathrm{Cl} 1.15$ 2.08) [31]. Interestingly, however, supplementary adjustment for major life stressors e.g. childhood trauma and/or work stress decreased the association substantially [32]. Another two-year follow-up study of adults aged 25-55 years in the US showed a bidirectional association between major depression and migraine [33]. Major depression at baseline predicted the first-onset migraine (OR 3.4, 95\% $\mathrm{Cl} 1.4-8.7$ ), and vice versa, migraine at baseline predicted the first-onset major depression (OR 5.8, 95\% $\mathrm{Cl}$ 2.7-12.3) [33].

Some previous cross-sectional studies have diagnosed depression using HADS score. Depression defined as HADS-D score of $\geq 11$ was more than two times more likely among individuals with migraine than non-migrainous headache based on cross-sectional data from HUNT2 [5]. Similarly, merged data of six previous EU-based cross-sectional studies reported that migraine was twice as common (OR 2.1, 95\% $\mathrm{Cl}$ 1.3-3.4) among individual with depression measured by HADS [34]. A recent meta-analysis based on data from cohort studies reported that migraineurs were almost twice (OR 1.81, 95\% $\mathrm{Cl} 1.20-2.72)$ as likely to develop depression as those without migraine [35].

In the present study, migraine with aura was associated with higher RR (1.7) of co-existing depression and anxiety than RR (1.3) of depression alone. A previous cross-sectional study showed that individuals with migraine with aura were more likely to be depressed compared to migraine without aura in women but not in men [8]. In the Michigan study, the risk for depression was almost twice as likely among migraine with aura compared to migraine without aura (ORs 4.0 vs 2.2) [36].

A bidirectional association between depression and TTH was also found in the present study. To our knowledge, data on such a relationship has not been provided for TTH in previous longitudinal studies. In cross-sectional population-based studies, divergent results have been reported for TTH. A recent population-based study performed in Korea reported that patients with TTH were almost two times more likely to have depression (4.2\% vs $1.8 \%$ ) than those without [37]. In contrast, a Nepalese population-based study found no association between depression and TTH [38]. Similarly, no association was found 
between depression measured by HADS and TTH in analyses using the merged data of six previous cross-sectional EU studies [34].

\section{Anxiety}

In the present study, we found that anxiety increased the risk of migraine, probable migraine, and TTH, and vice versa, that all these headache types increased the risk of anxiety.

Very few long-term prospective studies have evaluated the temporal bidirectional relationship between anxiety disorders and common primary headache disorders. Notably, prospective data of 591 young adults from Switzerland showed that the combination of major depression and anxiety disorder doubled the risk of migraine, and that anxiety disorders generally preceded the occurrence of migraine [9]. Furthermore, in a 1.2-year follow-up study of 1,007 adults aged 21-30 years, migraine at baseline increase the odds ratio of panic disorders with 12.8 [10]. Several cross-sectional population-based studies have reported evidence for positive associations between migraine and anxiety [5, 38-41]. In studies from Norway, the US and Canada, anxiety disorders were respectively 3.2, 3.1 and 2.5 times higher among migraineurs compared to headache-free individuals $[5,39,40]$. A recent systematic review evaluated the comorbidity of anxiety and migraine in the cohort studies, and estimated RR with an average of 1.63 [42].

In the present study, higher risk of anxiety was found for migraine with aura than for migraine without aura (1.8 vs 1. 39). In accordance with the present study, depression with comorbid anxiety was more likely among women with migraine with aura than among those without aura in a cross-sectional study based on HUNT2, whereas an association between anxiety alone and migraine with aura was not found [8]. In the Michigan study, the association between anxiety and migraine was slightly higher for migraine with aura than for migraine without aura (ORs 3.1 vs 2.3) [36].

Very few population-based cross-sectional studies have evaluated the impact of anxiety on TTH. A Korean population-based study reported that the prevalence of anxiety was almost twice as high ( $9.5 \%$ vs 5.3\%) among patients with TTH compared to headache-free controls [37]. Furthermore, TTH was associated with anxiety measured by HADS score both for males (ORs $2.5,95 \% \mathrm{Cl} 1.7-3.7$ ) and females (OR 1.5, 95\% Cl 1.1-2.1) based on data from six EU studies [34].In the present study, a bidirectional relationship between co-existence of anxiety and depression (defined as total HADS score of $\geq 15$ or $\geq 22$ ) was more evident for migraine than for TTH. For example, total HADS score $\geq 22$ at baseline was associated with more than four times increased risk of migraine at follow-up. In accordance, comorbidity of anxiety and depression was more strongly associated with increased risk of migraine than pure anxiety or depression in the Zurich study [41]. Furthermore, migraine was associated with increased OR of major depression combined with panic disorders 25.2 (95\% Cl 2.5-251) in the 1.2-year US follow-up study, whereas OR of $2.5(95 \% \mathrm{Cl} 1.0-6.5)$ was found for major depression alone [10].

\section{Interpretation}


The bidirectional relationship between affective disorders and migraine and TTH could be the results of shared pathophysiological mechanisms related to neurotransmitters, genetic basis and/or environmental factors. The follow-up studies from Canada demonstrated that life stressors such as childhood trauma may be an important common underlying factor, supporting the environmental aspect [13, 32]. Most previous studies focusing on the relationship between migraine and depression, suggest a common dysfunction related to serotonin, dopaminergic and GABAergic systems [43-45]. Furthermore, twin and family studies have indicated that the bilateral relationship between migraine and depression at least in part could be explained by genetic factors $[43,44,46]$. However, it is still unclear how specific genetic variants are associated with both the primary headaches and affective disorders.

\section{Strengths and limitations of the study}

The major strengths of this study are the prospective design, an 11-year follow-up period, and the large cohort from the adult population of an entire population of Trøndelag County. The present study design is more likely to identify causal relationships than cross-sectional studies. Furthermore, in the longitudinal analysis of risk factors at baseline, we have adjusted for the same confounding factors in all analyses, making the estimated RRs comparable. Finally, the study included use of validated diagnoses of headache $[22,23]$ and use of well-established cutoff score of HADS [18-20].

Several study limitations should also be addressed. Firstly, generalization of the results to the entire population must be made with caution, since the participation rate was $54 \%$ and $58 \%$ respectively in the two surveys, and only $36 \%$ of the invited population in HUNT3 participated in HUNT4. On the other hand, a bias in relative risk estimates will only arise if participation rates differ regarding headache status or affective disorders. The fact that neither headache nor anxiety and depression were primary objectives of these surveys makes selective participation and loss follow-up unlikely. Secondly, the diagnostic accuracy of questionnaire-based diagnoses of headache and affective disorders was not optimal, and the possibility of misclassification cannot be ruled out. However, most likely, such misclassification goes in both directions, decreasing the difference in RR between the diagnostic subgroups. The gold standard for the diagnosis of common primary headache disorders and affective disorders is the face-to-face interview by experts, but such strategy is not possible in large-scale population-based studies. Finally, the number of individuals with HADS score $\geq 11$ were relatively low. However, the associations studied were sufficiently powered to detect significant differences using the cut-off score $\geq 8$ and for the 8-10 HADS score groups.

\section{Conclusion}

In this large-scale population-based follow-up study, we found a bidirectional relationship between anxiety and depression and migraine and TTH. This result may indicate shared underlying pathophysiological mechanisms, and that effective management of affective disorders may hold the potential to reduce the incidence of migraine and TTH, and vice versa. 


\section{Abbreviations}

BMI: Body mass index; Cl: Confidence interval; DSM-5: Fifth version of the Diagnostic and Statistical Manual of Mental Disorders; GAD: Generalized anxiety disorder; HADS: Hospital Anxiety and depression Scale; HADS-A: Anxiety; HADS-D: Depression; HUNT: The Trøndelag Health Study; HUNT2: The second Trøndelag Health Study; HUNT3: The third Trøndelag Health Study; HUNT4: the fourth Trøndelag Health Study; RR: Risk ratio; TTH: Tension-type headache

\section{Declarations}

Ethics approval and consent to participate: This study was approved by the Regional Committee for Medical and Health Research Ethics, the Faculty of medicine, mailbox 8905, 7491 Trondheim. The approval number was \#2018/2422/Rek Midt. The participants have given written informed consent.

Consent for publication: The present study was approved by the HUNT Research Centre.

Availability of data and materials: Part of the dataset supporting the conclusions of this article is available on request to the corresponding author. Some of the data are the property of HUNT research Centre and can only be accessed through direct contact with. the research Centre.

Competing interests: The authors declare that they have no competing interests.

Funding: This research received no specific grant from any funding agency in the public, commercial, or not-for-profit sectors.

Authors' contributions: KH and SG analysed and interpreted the data received by the HUNT Research Centre. KH, SG and ET all had a major contributor in writing the manuscript. All authors read and approved the final manuscript.

Acknowledgements: The Trøndelag Health Study (The HUNT Study) is a collaboration between HUNT Research Centre, (Faculty of Medicine and Health Sciences, NTNU, Norwegian University of Science and Technology), Trøndelag County Council, Central Norway Regional Health Authority, and the Norwegian Institute of Public Health.

\section{References}

1. Global, regional, and national incidence, prevalence, and years lived with disability for 310 diseases and injuries, 1990-2015: a systematic analysis for the Global Burden of Disease Study 2015 (2016). Lancet 388:1545-1602 doi: 10.1016/S0140-6736(16)31678-6

2. GBD 2016 Headache Collaborators (2018) Global, regional, and national burden of migraine and tension-type headache, 1990-2016: a systematic analysis for the Global Burden of Disease Study 2016. Lancet Neurol 17:954-976 
3. Rehm J, Shield KD (2019) Global Burden of Disease and the Impact of Mental and Addictive Disorders. Curr Psychiatry Rep 21:10

4. Lipton RB, Hamelsky SW, Kolodner KB, Steiner TJ, Stewart WF (2000) Migraine, quality of life, and depression: a population-based case-control study. Neurology 55:629-635

5. Zwart JA, Dyb G, Hagen K, Dahl AA, Ødegård KJ, Bovim G et al (2003) Depression and anxiety disorders associated with headache frequency. The Nord-Trøndelag Health Study. Eur J Neurol 10:147-152

6. JetteN, Patten S, Williams J, Becker W, Samuel Wiebe S (2008) Comorbidity of migraine and psychiatric disorders-a national population-based study. Headache 48:501-516

7. Lantéri-MinetM, Radat F, Chautard MH, Lucas C (2005) Anxiety and depression associated with migraine: influence on migraine subjects' disability and quality of life, and acute migraine management. Pain 118:319-326

8. Oedegaard KJ, Neckelmann D, Mykletun A, Dahl AA, Zwart JA, Hagen K, Fasmer OB (2006) Migraine with and without aura: Association with depression and anxiety disorder in a population-based study. The HUNT Study. Cephalalgia 26:1-6

9. Merikangas KR, Merikangas JR, Angst J (1993) Headache syndromes and psychiatric disorders: association and familial transmission. J Psychiatr Res 27:197-210

10. Breslau N, Davis GC (1993) Migraine, physical health and psychiatric disorder: a prospective epidemiologic study in young adults. J Psychiatr Res 27: 211-221

11. Swartz KL, Pratt LA, Armenian HK, Lee LC, Eaton WW (2000) Mental disorders and the incidence of migraine headaches in a community sample: results from the Baltimore Epidemiologic Catchment area follow-up study. Arch Gen Psychiatry 57: 945-450

12. PattenSB', Williams JVA, Lavorato DH, Modgill G, Jetté N, Eliasziw M (2008) Major depression as a risk factor for chronic disease incidence: longitudinal analyses in a general population cohort. Gen Hosp Psychiatry 2008 30:407-413

13. ModgillG, Jette N, Wang JL, Becker WJ, Patten SB (2012) A population-based longitudinal community study of major depression and migraine. Headache 52:422-432

14. Rist PM, Schürks M, Buring JE, Kurth T (2013) Migraine, headache, and the risk of depression: Prospective cohort study. Cephalalgia 33:1017-1025

15. Hagen, K, Stovner, LJ, Zwart, JA (2020) Time trends of major headache diagnoses and predictive factors. Data from three Nord-Trøndelag health surveys. The Journal of Headache and Pain 21(24)

16. Krokstad S, Langhammer A, Hveem K, Holmen TL, Midthjell K, Stene TR et al (2013) Cohort profile: the HUNT Study, Norway. Int J Epidemiol 42:968-977

17. Åsvold BO, Langhammer A, Rehn TA, Kjelsvik G, Grøntvedt TV, Sørgjerd EP et al (2021) Cohort Profile update; The HUNT Study, Norway. MedRxiv https://www.medrxiv.org/content/10.1101/2021.10.12.21264858v1 
18. Mykletun A, Stordal E, Dahl AA (2018) Hospital Anxiety and Depression (HAD) scale: Factor structure, item analyses and internal consistency in a large population. British Journal of Psychiatry 179:540544

19. Bjelland I, Dahl AA, Haug TT, Neckelmann D (2002) The validity of the Hospital Anxiety and Depression Scale. An updated literature review. J Psychosom Res 52:69-77

20. Zigmond AS, Snaith RP (1983) The Hospital Anxiety and Depression Scale. Acta Psychiatrica Scandinavica 67:361-370

21. Headache Classification Committee of the International Headache Society (IHS) (2018) The International Classification of Headache Disorders (IHS), 3rd edition. Cephalalgia 38:1-211

22. Hagen K, Zwart JA, Aamodt AH, Nilsen KB, Bråthen G, Helde G et al (2010) The validity of questionnaire-based diagnoses: The third Nord-Trøndelag Health Study 2006-2008. J Headache Pain 11:67-73

23. Hagen K, Åsberg AN, Uhlig BL, Tronvik E, Brenner E, Sand T (2019) HUNT4: The validity of questionnaire-based diagnoses. J Headache Pain 20:70

24. E Stordal, Krüger MB, Dahl NH, Krüger $\varnothing$, Mykletun A, Dahl AA (2001) Depression in relation to age and gender in the general population: the Nord-Trøndelag Health Study (HUNT). Acta Psychiatr Scand 104:210-216

25. Linde M, Stovner LJ, Zwart JA, Hagen K (2011) Time trends in the prevalence of headache disorders. The Nord-Trondelag Health Studies (HUNT 2 and HUNT 3). Cephalalgia 31:585-96

26. Bjellandl, Krokstad S, Mykletun A, Dahl AA, Tell GS, Tambs K (2008) Does a higher educational level protect against anxiety and depression? The HUNT study. Sos Sci Med 66:1334-1345

27. Hagen K, Vatten L, Stovner LJ, Zwart JA, Krogstad S, Bovim G (2002) Low socio-economic status is associated with increased risk of frequent headache. A prospective study of 22718 adults in Norway. Cephalalgia 22: 672-679

28. Mykletun A, Overland S, Aarø LE, Liabø HM, Stewart R (2008) Smoking in relation to anxiety and depression: evidence from a large population survey: the HUNT study. Eur Psychiatry 23;77-84

29. Aamodt AH, Hagen K, Bråthen G, Zwart JA, Stovner LJ (2006) Headache prevalence related to smoking and alcohol use. The Head-HUNT study. Eur J Neurol 13:1233-1238

30. Johnsen MB, Winsvold BS, Børte S, Vie GÅ, Pedersen LM, Storheim K et al (2018) The causal role of smoking on the risk of headache. A Mendelian randomization analysis in the HUNT Study. Eur J Neurol 25:1148-e102

31. Hagen K, Åsberg A, Stovner LJ, Linde M, Zwart JA, Heuch I (2018) Lifestyle factors and risk of migraine and tension-type headache. Follow-up data from the Nord-Trøndelag Health Surveys 199597 and 2006-2008. Cephalalgia 38:1919-1926

32. Swanson SA, Zeng Y, Weeks M, Colman I (2013) The contribution of stress to the comorbidity of migraine and major depression: results from a prospective cohort study. BMJ Open 3(3) 
33. Breslau N, Lipton RB, Stewart WF, Schultz LR, Welch KM (2003) Comorbidity of migraine and depression: investigating potential etiology and prognosis. Neurology 60:1308-1312.

34. Lampl C, Thomas H, Tassorelli C, Katsarava Z, Laínez JM, Lantéri-Minet M et al (2016) Headache, depression and anxiety: associations in the Eurolight project. J Headache Pain 17:59.

35. Amiri S, Behnezhad S, Azad E (2019) Migraine headache and depression in adults: a systematic Review and Meta-analysis. Neuropsychiatrie 33:131-140.

36. Breslau N, Davis GC, Andreski P (1991) Migraine, psychiatric disorders, and suicide attempts: an epidemiologic study of young adults. Psychiatry research 37:11-23.

37. Song T-J, Cho S-J, Kim W-J, Yang KI, Yun C-H, Chu MK (2016) Anxiety and Depression in TensionType Headache: A Population-Based Study. PloS one 11: e0165316.

38. Risal A, Manandhar K, Holen A, Steiner TJ, Linde M (2016) Comorbidities of psychiatric and headache disorders in Nepal: implications from a nationwide population-based study. J Headache Pain 17:45.

39. McWilliams LA, Goodwin RD, Cox BJ (2004) Depression and anxiety associated with three pain conditions: results from a nationally representative sample. Pain 111 (1)

40. Fuller-Thomson E, Jayanthikumar J, Agbeyaka SK (2017) Untangling the Association Between Migraine, Pain, and Anxiety: Examining Migraine and Generalized Anxiety Disorders in a Canadian Population Based Study. Headache 57:375-390.

41. Merikangas KR, Angst J, Isler H (1990) Migraine and psychopathology. Results of the Zurich cohort study of young adults. Arch Gen Psychiatry 47:849-853.

42. Karimi L, Wijeratne T, Crewther SG, Evans AE, Ebaid D, Khalil H (2021) The Migraine-Anxiety Comorbidity Among Migraineurs: A Systematic Review. Frontiers in Neurology 11(1782)

43. Yang Y, Ligthart L, Terwindt GM, Boomsma DI, Rodriguez-Acevedo AJ, Nyholt DR (2016) Genetic epidemiology of migraine and depression. Cephalalgia 36:679-691

44. Ligthart L, Nyholt DR, Penninx BW, Boomsma DI (2010) The shared genetics of migraine and anxious depression. Headache 50:1549-1560 doi: 10.1111/j.1526-4610.2010.01705.x

45. Altamura C, Corbelli I, de Tommaso M, Di Lorenzo C, Di Lorenzo G, Di Renzo A, Filippi M, Jannini TB, Messina R, Parisi P, Parisi V, Pierelli F, Rainero I, Raucci U, Rubino E, Sarchielli P, Li L, Vernieri F, Vollono C, Coppola G (2021) Pathophysiological Bases of Comorbidity in Migraine Front Hum Neurosci 15:640574

46. Stam AH, de Vries B, Janssens AC, Vanmolkot KR, Aulchenko YS, Henneman P et al (2010) Shared genetic factors in migraine and depression: evidence from a genetic isolate. Neurology 74:288-294.

\section{Tables}

Table 1 Baseline characteristics of population at risk in HUNT3 with valid data in HUNT4 defined as respectively without headache and with anxiety and depression HADS ${ }^{1}$ score of $\leq 7$ 


\begin{tabular}{|c|c|c|}
\hline \multirow[b]{2}{*}{ Characteristics } & \multicolumn{2}{|c|}{ Population at risk in HUNT3 } \\
\hline & Without headache & HADS score $\leq 7$ \\
\hline Number of participants with valid data in HUNT4 & 13,893 & 18,380 \\
\hline Women $(\%)($ missing $=0)$ & 52.6 & 57.6 \\
\hline Mean age, years $(\mathrm{SD})($ missing $=0$ ) & $54.6(13.1)$ & $52.3(13)$ \\
\hline$\geq 13$ years of education $(\%)$ (missing $=0$ ) & 36.1 & 38.8 \\
\hline Current smoking, $n(\%)$ (missing=308/363) & 12.6 & 12.9 \\
\hline Mean $\mathrm{BMI}^{2}, \mathrm{~kg} / \mathrm{m}^{2}(\mathrm{SD})$ (missing $\left.=16 / 28\right)$ & $27.1(4.1)$ & $27.1(4.2)$ \\
\hline Mean HADS- $A^{3}(S D)($ missing $=303 / 0)$ & $3.5(3.0)$ & $2.9(2.1)$ \\
\hline Mean HADS-D ${ }^{4}(S D)$ (missing=247/0) & $3.0(2.7)$ & $2.4(2.0)$ \\
\hline Mean total HADS ${ }^{1}$ score (missing $=0$ ) & $6.5(4.9)$ & $5.3(3.3)$ \\
\hline Alcohol abstainers last year (\%) (missing=243/287) & 6.6 & 6.1 \\
\hline Self-reported hypertension, $\mathrm{n}(\%) \quad$ (missing=0) & 21.2 & 18.4 \\
\hline Self-reported stroke (\%) (missing=0) & 1.8 & 1.6 \\
\hline Self-reported diabetes mellitus, $\mathrm{n}(\%)$ (missing=0) & 4.2 & 3.5 \\
\hline Headache $(\%)($ missing $=0)$ & 0 & 35.7 \\
\hline
\end{tabular}

${ }^{1}$ HADS=Hospital Anxiety and Depression Scale; ${ }^{2} \mathrm{BMI}=$ body mass index; ${ }^{3} \mathrm{HADS}-\mathrm{A}$ : Anxiety score; ${ }^{4} \mathrm{HADS}-$ D: Depression score

Table 2. Headache free individuals in HUNT3 $(n=13,893)$ : Risk of migraine and tension-type headache in HUNT4 based on HADS ${ }^{1}$ score categories in HUNT3 evaluated by poisson regression with $95 \%$ confidence interval. 


$\begin{array}{llll}\text { Number } & \begin{array}{l}\text { Definite migraine } \\ (\mathrm{n}=273)\end{array} & \begin{array}{l}\text { Tension-type headache } \\ (\mathrm{n}=1436)\end{array} & \begin{array}{l}\text { Problable migraine } \\ (\mathrm{n}=229)\end{array} \\ \mathrm{RR}(95 \% \mathrm{Cl}) & \mathrm{RR}(95 \% \mathrm{Cl}) & \mathrm{RR}(95 \% \mathrm{Cl})\end{array}$

Model 1 (Adjusted for age, gender and education level)

\begin{tabular}{|lllll|}
$\begin{array}{l}\text { HADS-A } \\
\leq 7\end{array}$ & 12,276 & 1.00 & 1.00 & 1.00 \\
\hline $8-10$ & 936 & $1.82(1.27-2.61)$ & $1.45(1.23-1.71)$ & $1.90(1.28-2.80)$ \\
\hline 11 & 378 & $1.77(0.98-3.19)$ & $1.41(1.11-1.80)$ & $1.65(0.88-3.09)$ \\
\hline $\begin{array}{l}\text { HADS-D } \\
\leq 7\end{array}$ & 12,677 & 1.00 & 1.00 & 1.00 \\
\hline $8-10$ & 777 & $2.20(1.43-3.38)$ & $1.49(1.24-1.80)$ & $1.45(0.85-2.48)$ \\
\hline$\geq 11$ & 192 & $2.28(1.01-5.14)$ & $1.11(0.72-1.69)$ & $1.80(0.68-4.74)$ \\
\hline $\begin{array}{l}\text { Total } \\
14\end{array}$ & 12,877 & 1.00 & 1.00 & 1.00 \\
\hline $15-21$ & 871 & $1.81(1.19-2.74)$ & $1.57(1.33-1.86)$ & $1.42(0.87-2.30)$ \\
\hline$\geq 22$ & 145 & $4.89(2.59-9.24)$ & $1.70(1.17-2.48)$ & $3.34(1.51-7.38)$ \\
\hline
\end{tabular}

Model 2 (Adjusted for age, gender, education level, smoking status and body mass index)

\begin{tabular}{|lllll|}
$\begin{array}{l}\text { HADS-A } \\
\leq 7\end{array}$ & 12,276 & 1.00 & 1.00 & 1.00 \\
\hline$\geq 8$ & 1314 & $1.75(1.27-2.42)$ & $1.42(1.23-1.64)$ & $1.76(1.24-2.49)$ \\
\hline $8-10$ & 936 & $1.77(1.24-2.53)$ & $1.44(1.22-1.70)$ & $1.83(1.24-2.72)$ \\
\hline$\geq 11$ & 378 & $1.71(0.95-3.09)$ & $1.38(1.08-1.77)$ & $1.59(0.85-2.98)$ \\
\hline $\begin{array}{l}\text { HADS-D } \\
\leq 7\end{array}$ & 12,677 & 1.00 & 1.00 & 1.00 \\
$\geq 8$ & 969 & $2.15(1.45-3.18)$ & $1.41(1.18-1.67)$ & $1.45(0.90-2.35)$ \\
\hline $8-10$ & 777 & $2.13(1.38-3.29)$ & $1.48(1.23-1.79)$ & $1.39(0.81-2.38)$ \\
\hline$\geq 11$ & 192 & $2.21(0.99-4.92)$ & $1.11(0.72-1.70)$ & $1.79(0.67-4.76)$ \\
\hline $\begin{array}{l}\text { Total } \\
14\end{array}$ & 12,877 & 1.00 & 1.00 & 1.00 \\
\hline$\geq 15$ & 1016 & $2.10(1.46-3.04)$ & $1.57(1.34-1.84)$ & $1.58(1.03-2.43)$ \\
\hline $15-21$ & 871 & $1.74(1.14-2.66)$ & $1.56(1.32-1.85)$ & $1.35(0.83-2.21)$ \\
\hline$\geq 22$ & 145 & $4.54(2.39-8.60)$ & $1.64(1.11-2.41)$ & $3.20(1.44-7.13)$ \\
\hline
\end{tabular}


${ }^{1}$ Hospital Anxiety and Depression Scale score; ${ }^{2}$ HADS-A: Anxiety score; ${ }^{3}$ HADS-D: Depression score; ${ }^{4}$ Total HADS score

Table 3. HADS ${ }^{1}$ anxiety and depression score $\leq 7$ in HUNT3 ( $\left.n=18,380\right)$ : Risk of elevated HADS ${ }^{1}$ score in HUNT4 based on headache diagnoses in HUNT3 evaluated by poisson regression with $95 \%$ confidence interval. 


\begin{tabular}{|c|c|c|c|c|c|c|}
\hline \multirow[b]{2}{*}{ Number } & \multicolumn{2}{|c|}{ HADS anxiety score } & \multicolumn{2}{|c|}{$\begin{array}{l}\text { HADS depression } \\
\text { score }\end{array}$} & \multicolumn{2}{|c|}{ Total HADS score } \\
\hline & $\begin{array}{l}8-10 \\
(n=1228)\end{array}$ & $\begin{array}{l}\geq 11 \\
(n=349)\end{array}$ & $\begin{array}{l}8-10 \\
(n=751)\end{array}$ & $\begin{array}{l}\geq 11 \\
(\mathrm{n}=182)\end{array}$ & $\begin{array}{l}15-21 \\
(n=862)\end{array}$ & $\begin{array}{l}\geq 22 \\
(\mathrm{n}=131)\end{array}$ \\
\hline & $\begin{array}{l}\mathrm{RR}(95 \% \\
\mathrm{Cl})\end{array}$ & $\begin{array}{l}\mathrm{RR}(95 \% \\
\mathrm{Cl})\end{array}$ & $\begin{array}{l}\mathrm{RR}(95 \% \\
\mathrm{Cl})\end{array}$ & $\begin{array}{l}\mathrm{RR}(95 \% \\
\mathrm{Cl})\end{array}$ & $\begin{array}{l}\mathrm{RR}(95 \% \\
\mathrm{Cl})\end{array}$ & $\begin{array}{l}\mathrm{RR}(95 \% \\
\mathrm{Cl})\end{array}$ \\
\hline
\end{tabular}

Model 1: Adjusted for age, gender and education level

\begin{tabular}{|c|c|c|c|c|c|c|c|}
\hline $\begin{array}{l}\text { Headache } \\
\text { free }\end{array}$ & 11,819 & 1.00 & 1.00 & 1.00 & 1.00 & 1.00 & 1.00 \\
\hline $\mathrm{TTH}^{2}$ & 3063 & $\begin{array}{l}1.34 \\
(1.10- \\
1.55)\end{array}$ & $\begin{array}{l}1.19 \\
(0.90- \\
1.57)\end{array}$ & $\begin{array}{l}1.40 \\
(1.16- \\
1.69)\end{array}$ & $\begin{array}{l}0.93 \\
(0.60- \\
1.43)\end{array}$ & $\begin{array}{l}1.21 \\
(1.01- \\
1.44)\end{array}$ & $\begin{array}{l}1.04 \\
(0.64- \\
1.68)\end{array}$ \\
\hline $\begin{array}{l}\text { Definite } \\
\text { migraine }\end{array}$ & 1962 & $\begin{array}{l}1.71 \\
(1.46- \\
2.00)\end{array}$ & $\begin{array}{l}1.33 \\
(0.97- \\
1.81)\end{array}$ & $\begin{array}{l}1.27 \\
(1.00- \\
1.63)\end{array}$ & $\begin{array}{l}1.36 \\
(0.87- \\
2.12)\end{array}$ & $\begin{array}{l}1.52 \\
(1.24- \\
1.85)\end{array}$ & $\begin{array}{l}1.10 \\
(0.63- \\
1.91)\end{array}$ \\
\hline $\begin{array}{l}\text { Without } \\
\text { aura }\end{array}$ & 1038 & $\begin{array}{l}1.61 \\
(1.31- \\
1.96)\end{array}$ & $\begin{array}{l}0.72 \\
(0.42- \\
1.21)\end{array}$ & $\begin{array}{l}1.35 \\
(0.98- \\
1.85)\end{array}$ & $\begin{array}{l}0.86 \\
(0.42- \\
1.77)\end{array}$ & $\begin{array}{l}1.34 \\
(1.02- \\
1.76)\end{array}$ & $\begin{array}{l}0.39 \\
(0.12- \\
1.29)\end{array}$ \\
\hline With aura & 924 & $\begin{array}{l}1.83 \\
(1.50- \\
2.29)\end{array}$ & $\begin{array}{l}2.02 \\
(1.42- \\
2.88)\end{array}$ & $\begin{array}{l}1.19 \\
(0.84- \\
1.70)\end{array}$ & $\begin{array}{l}1.91 \\
(1.13- \\
3.22)\end{array}$ & $\begin{array}{l}1.71 \\
(1.31- \\
2.21)\end{array}$ & $\begin{array}{l}1.90 \\
(1.04- \\
3.35)\end{array}$ \\
\hline $\begin{array}{l}\text { Probable } \\
\text { migraine }\end{array}$ & 1252 & $\begin{array}{l}1.32 \\
(1.07- \\
1.62)\end{array}$ & $\begin{array}{l}1.33 \\
(0.91- \\
1.94)\end{array}$ & $\begin{array}{l}1.19 \\
(0.90- \\
1.59)\end{array}$ & $\begin{array}{l}1.24 \\
(0.72- \\
2.18)\end{array}$ & $\begin{array}{l}1.45 \\
(1.14- \\
1.85)\end{array}$ & $\begin{array}{l}1.13 \\
(0.59- \\
2.21)\end{array}$ \\
\hline
\end{tabular}

Model 2: Adjusted for age, gender, education level, smoking status and body mass index

\begin{tabular}{|c|c|c|c|c|c|c|c|}
\hline $\begin{array}{l}\text { Headache } \\
\text { free }\end{array}$ & 11,819 & 1.00 & 1.00 & 1.00 & 1.00 & 1.00 & 1.00 \\
\hline TTH $^{2}$ & 3063 & $\begin{array}{l}1.34 \\
(1.16- \\
1.57)\end{array}$ & $\begin{array}{l}1.18 \\
(0.89- \\
1.56)\end{array}$ & $\begin{array}{l}1.40 \\
(1.16- \\
1.68)\end{array}$ & $\begin{array}{l}0.92 \\
(0.59- \\
1.42)\end{array}$ & $\begin{array}{l}1.21 \\
(1.01- \\
1.44)\end{array}$ & $\begin{array}{l}1.03 \\
(0.64 \\
1.67)\end{array}$ \\
\hline $\begin{array}{l}\text { Definite } \\
\text { migraine }\end{array}$ & 1962 & $\begin{array}{l}1.69 \\
(1.45- \\
1.98)\end{array}$ & $\begin{array}{l}1.29 \\
(0.94- \\
1.77)\end{array}$ & $\begin{array}{l}1.25 \\
(0.98- \\
1.61)\end{array}$ & $\begin{array}{l}1.29 \\
(0.82- \\
2.02)\end{array}$ & $\begin{array}{l}1.49 \\
(1.22- \\
1.82)\end{array}$ & $\begin{array}{l}1.00 \\
(0.57 \\
1.74)\end{array}$ \\
\hline $\begin{array}{l}\text { Without } \\
\text { aura }\end{array}$ & 1038 & $\begin{array}{l}1.61 \\
(1.31- \\
1.96)\end{array}$ & $\begin{array}{l}0.72 \\
(0.42- \\
1.21)\end{array}$ & $\begin{array}{l}1.35 \\
(0.98- \\
1.85)\end{array}$ & $\begin{array}{l}0.86 \\
(0.42- \\
1.77)\end{array}$ & $\begin{array}{l}1.34 \\
(1.02- \\
1.76)\end{array}$ & $\begin{array}{l}0.39 \\
(0.12 \\
1.29)\end{array}$ \\
\hline With aura & 924 & $\begin{array}{l}1.83 \\
(1.50- \\
2.29)\end{array}$ & $\begin{array}{l}2.02 \\
(1.42- \\
2.88)\end{array}$ & $\begin{array}{l}1.19 \\
(0.84- \\
1.70)\end{array}$ & $\begin{array}{l}1.91 \\
(1.13- \\
3.22)\end{array}$ & $\begin{array}{l}1.71 \\
(1.31- \\
2.21)\end{array}$ & $\begin{array}{l}1.90 \\
(1.04 \\
3.35)\end{array}$ \\
\hline $\begin{array}{l}\text { Probable } \\
\text { migraine }\end{array}$ & 1252 & $\begin{array}{l}1.30 \\
(1.06- \\
1.60)\end{array}$ & $\begin{array}{l}1.31 \\
(0.89- \\
1.92)\end{array}$ & $\begin{array}{l}1.19 \\
(0.89- \\
1.58)\end{array}$ & $\begin{array}{l}1.24 \\
(0.71- \\
2.17)\end{array}$ & $\begin{array}{l}1.44 \\
(1.13- \\
1.82)\end{array}$ & $\begin{array}{l}1.11 \\
(0.57 \\
2.16)\end{array}$ \\
\hline
\end{tabular}


${ }^{1}$ Hospital Anxiety and Depression Scale; ${ }^{2}$ Tension-type headache

Table 4. HADS ${ }^{1}$ anxiety and depression score $\leq 7$ in HUNT3 ( $\left.n=18,380\right)$ : Risk of elevated HADS ${ }^{1}$ score in HUNT4 based on headache diagnoses in HUNT3 evaluated by poisson regression with $95 \%$ confidence interval.

\begin{tabular}{|c|c|c|c|c|}
\hline & Number & $\begin{array}{l}\text { HADS-A } \geq 8 \\
(n=1577)\end{array}$ & $\begin{array}{l}\text { HADS-D } \geq 8 \\
(n=933)\end{array}$ & $\begin{array}{l}\text { Total HADS } \geq 15 \\
(\mathrm{n}=993)\end{array}$ \\
\hline & & $\mathrm{RR}(95 \% \mathrm{Cl})$ & $\mathrm{RR}(95 \% \mathrm{Cl})$ & $\mathrm{RR}(95 \% \mathrm{Cl})$ \\
\hline \multicolumn{5}{|l|}{ Model 1} \\
\hline Headache free & 11,819 & 1.00 & 1.00 & 1.00 \\
\hline TTH $^{2}$ & 3063 & $1.30(1.14-1.47)$ & $1.30(1.10-1.54)$ & $1.18(1.00-1.40)$ \\
\hline Definite migraine & 1962 & $1.60(1.36-1.83)$ & $1.29(1.04-1.60)$ & $1.45(1.20-1.75)$ \\
\hline Without aura & 1038 & $1.39(1.15-1.67)$ & $1.24(0.93-1.65)$ & $1.20(0.93-1.56)$ \\
\hline With aura & 924 & $1.83(1.55-2.17)$ & $1.36(1.02-1.81)$ & $1.73(1.37-2.18)$ \\
\hline $\begin{array}{l}\text { Probable } \\
\text { migraine }\end{array}$ & 1252 & $1.31(1.10-1.56)$ & $1.20(0.93-1.54)$ & $1.39(1.12-1.74)$ \\
\hline \multicolumn{5}{|l|}{ Model 2} \\
\hline Headache free & 11,819 & 1.00 & 1.00 & 1.00 \\
\hline $\mathrm{TTH}^{2}$ & 3063 & $1.29(1.14-1.47)$ & $1.30(1.10-1.54)$ & $1.18(1.00-1.39)$ \\
\hline Definite migraine & 1962 & $1.59(1.38-1.82)$ & $1.26(1.02-1.56)$ & $1.42(1.17-1.71)$ \\
\hline Without aura & 1038 & $1.39(1.15-1.67)$ & $1.22(0.91-1.62)$ & $1.18(0.99-1.39)$ \\
\hline With aura & 924 & $1.81(1.52-2.14)$ & $1.31(0.99-1.62)$ & $1.67(1.32-2.10)$ \\
\hline $\begin{array}{l}\text { Probable } \\
\text { migraine }\end{array}$ & 1252 & $1.30(1.09-1.56)$ & $1.19(0.92-1.53)$ & $1.38(1.11-1.72)$ \\
\hline
\end{tabular}

${ }^{1}$ Hospital Anxiety and Depression Scale score; ${ }^{2}$ Tension-type headache

\section{Figures}


HUNT3 2006-2008

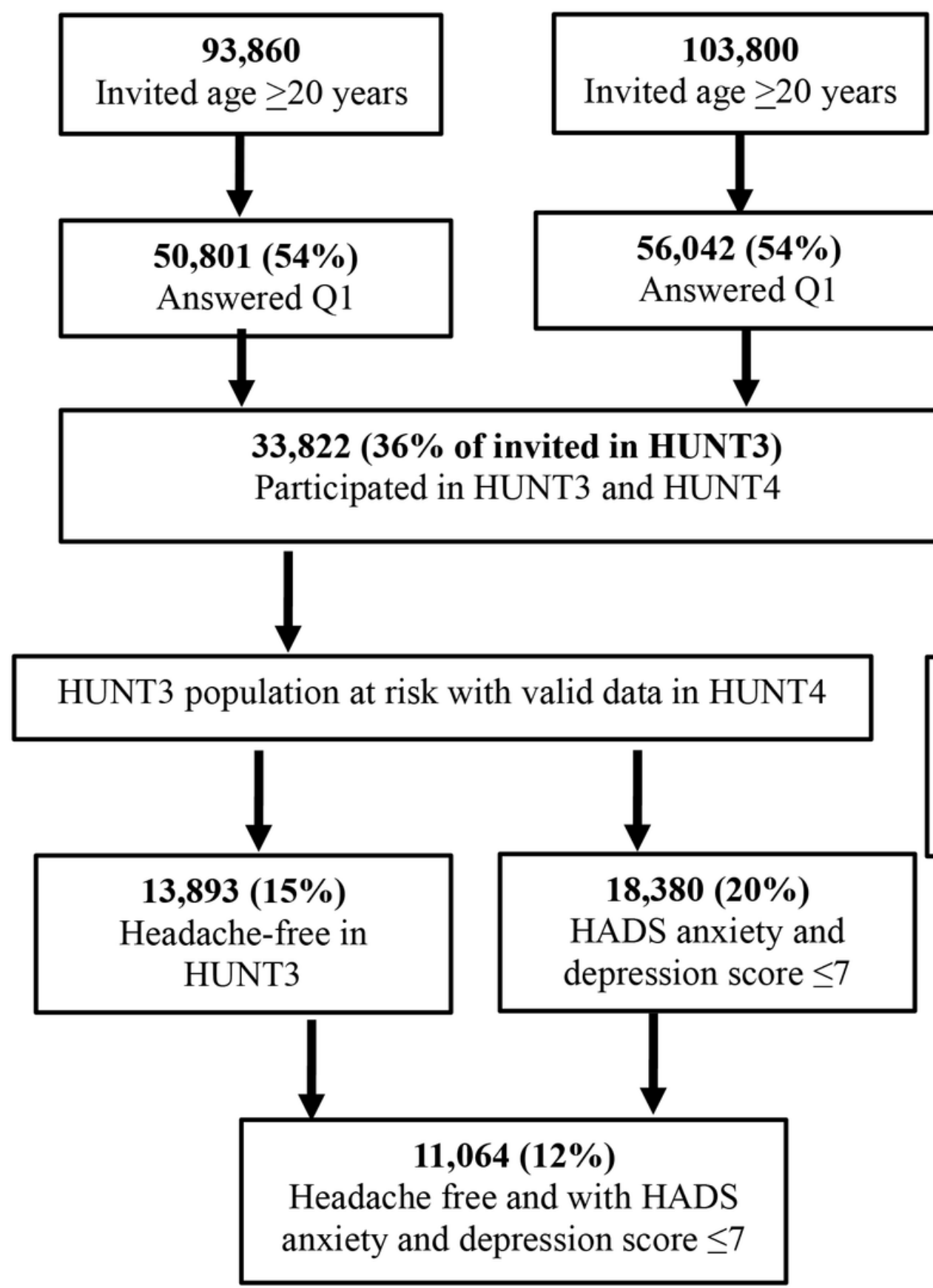

HUNT4 2017-2019

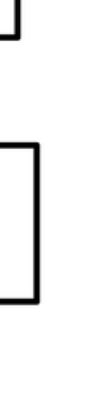

